\title{
Téoros
}

Revue de recherche en tourisme

\section{Les Laurentides, quelles Laurentides ?}

\section{Normand Cazelais}

Volume 15, numéro 1, printemps 1996

Les Laurentides, quelles Laurentides?

URI : https://id.erudit.org/iderudit/1075044ar

DOI : https://doi.org/10.7202/1075044ar

Aller au sommaire du numéro

Éditeur(s)

Université du Québec à Montréal

ISSN

0712-8657 (imprimé)

1923-2705 (numérique)

Découvrir la revue

Citer ce document

Cazelais, N. (1996). Les Laurentides, quelles Laurentides ? Téoros, 15(1), 2-3.

https://doi.org/10.7202/1075044ar d'utilisation que vous pouvez consulter en ligne.

https://apropos.erudit.org/fr/usagers/politique-dutilisation/ 


\section{Présentation: LES LAUREvTiDES, \\ Normand Cazelais}

Normand Cazelais

journaliste et géographe à Hydro-Québec.
La question en effet vaut d'être posée. Si elles présentent une évidente homogénéité dans leur allure physique, les Laurentides, cette frange méridionale du vaste ensemble cristallin du Bouclier canadien, sont multiples et variées dans les vocations et paysages que leur ont imprimés les activités humaines au cours des générations.

De quelles Laurentides s'agit-il? Le vocabulaire courant et les désignations officielles véhiculent des interprétations différentes. Tant les gens de Québec et de Trois-Rivières que de Mantréal et de Hull parlent des Laurentides quand ils réfèrent à cette vaste zone montagneuse et lacustre qui est d̀ leurs portes. Pourtant, à part la Réserve faunique des Laurentides sise entre Québec et le Saguenay, seule l'étroite région s'étendant au nord-ouest de Montréal a droit au toponyme Laurentides, à preuve les appellations de I'Association touristique des Laurentides (ATL) et de la Municipalité régionale de comté des Laurentides.

Les Laurentides touristiques ne correspondent pas au seul couloir de la vallée de la rivière du Nord et du double sillon de la route 117 et de l'autoroute dite des Laurentides. Ce numéro de Téoros sintéresse au vaste territoire qui comprend tout autant l'Outaouais et Lanaudière que l'espace proprement dit de I'ATL. Les textes qui le composent se complètent ot se répondent, abordant lidentité et le développoment des

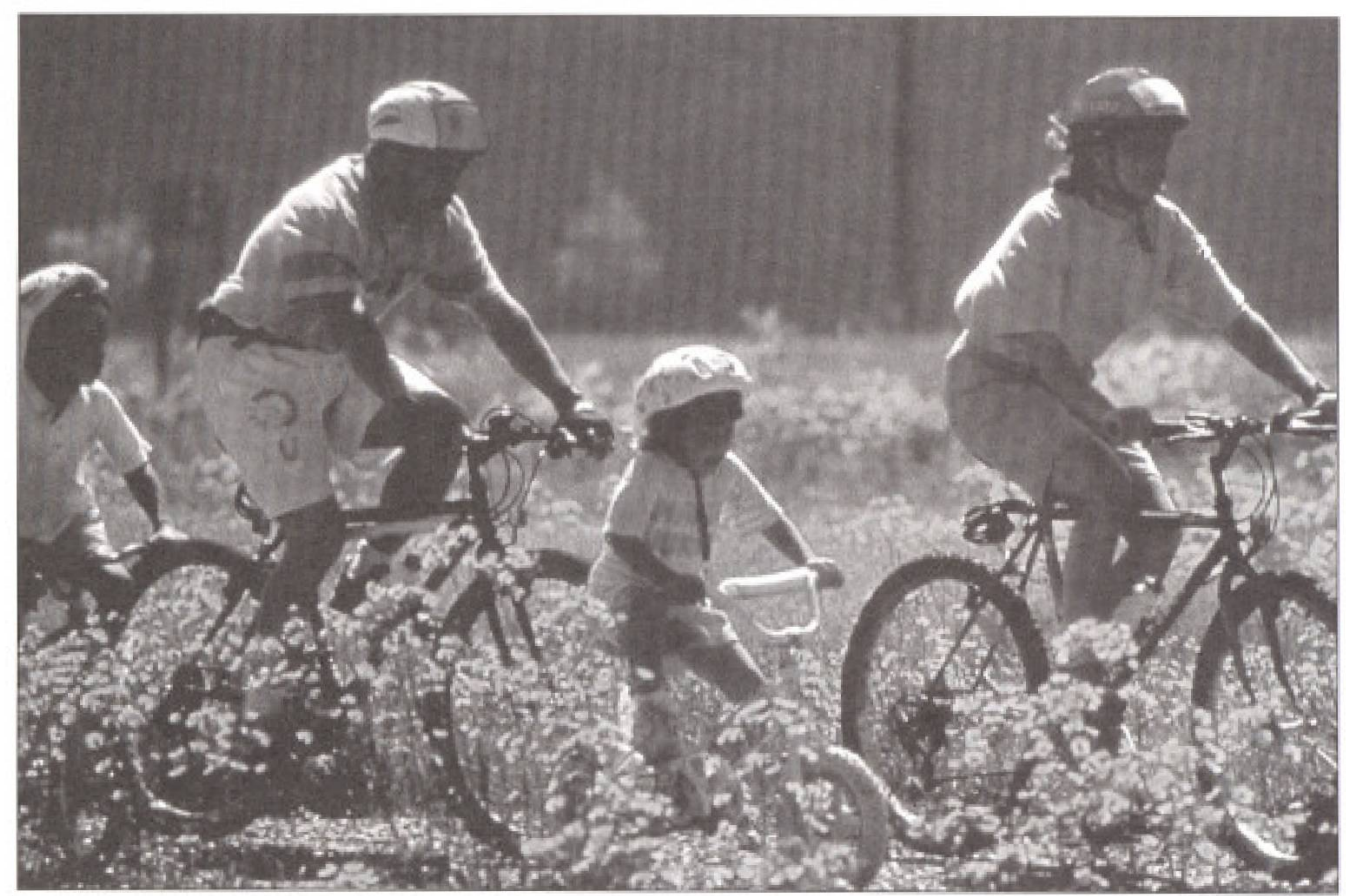

phs complexe que celle reflétée dans la littérature de promotion touristiquen, qui exigerait une meilleure prise en compte l'approche géographique dans cette promotion touristique.

Par la lunette de l'histoire, Gérard Beaudet porte son regard sur les diverses strates d'occupation humaine qui se sont succédées et superposées dans les Laurentides. En faisant un survol de leur aménagement touristique depuis la fin du XIXe siècle, il explique que la villégiature et le tourisme axés sur les activités de plein air sy sont déployés wdans un milieu humain qui leur préexistaitw. w/l en aura constitué, écrit-il, le cadre d'inscription et, dans la póriode pionnière, la matière premièren où la villégiature, le tourisme de façon plus générale uont rapidement produit leur propre environnement et un paysage de plus en plus caractérisén.
Laurentides sous l'angle du tourisme pris dans des considérations économiques, sociales, culturelles, historiques ou même géomorphologiques. II s'en dégage un portrait inédit, mettant en relief, c'est le cas de le dire, les différences, particularités et traits communs des diverses composantes de ce uterrain de jeum que sont largement devenues les Laurentides.

Dès le départ, lanalyse de Claude Lamothe relève la place importante que tiennent toujours, en sus du tourisme, les espaces consacrés à la foresterie, à l'agriculture et à la conservation. Soulignant la présence d'une trentaine d'entités spatiales différentes dont wenviron quatre ou cinq concernent la majorité des installations touristiques", elle révèle une organisation abeaucoup
Constatant que loffre touristique des Laurentides est bien connue, Jean Stafford, en étudie la demande. Pour ce faire, il en scrute, dans ses mouvements tendanciels, saisonniers, cycliques et irréguliers, l'évolution des chambres occupées, «seul indica. tour vraiment touristique utilisable au plan statistiquen.

La croissance utrès faible des chambres disponibles et la demande "stagnanten des chambres occupées interpollent à son avis, une réflexion sur les forces et faiblesses de la région, liées en bonne partie, au fait que les Laurentides sont devenues un wimmense parc de loisir et non une destination touristique digne de ce nom. Le agrand defin sera donc de concilier ces deux vocations. 


\section{QuEuEs LAuREvTiDes?}

Dans son dernier ouvrage, Chronique de l'hospitalité hötelière du Québec de 1940 à 1980, Henri-Paul Garceau s'est penché sur un pan d'histoire négligé, celui de l'organisation du tourisme dans les régions du Québec. Les extraits cités ici rappelient les débuts de la grande hôtellerie dans les Laurentides de Montréal et lémergence conséquente de ses principaux centres de villégiature. Leur lecture permet d'évaluer le chemin parcouru et les effets à long terme de leur implantation dans lorganisation du produit touristique du wcoeurn des Laurentides.

Louis Jolin, pour sa part, retrace l'apport, woin d'étre marginaliv, des colonies de vacances pour jeunes, des camps familiaux ou spécialisés, des bases de plein-air et de tous ces établissements de atourisme socialn a la vocation touristique des Laurentides.

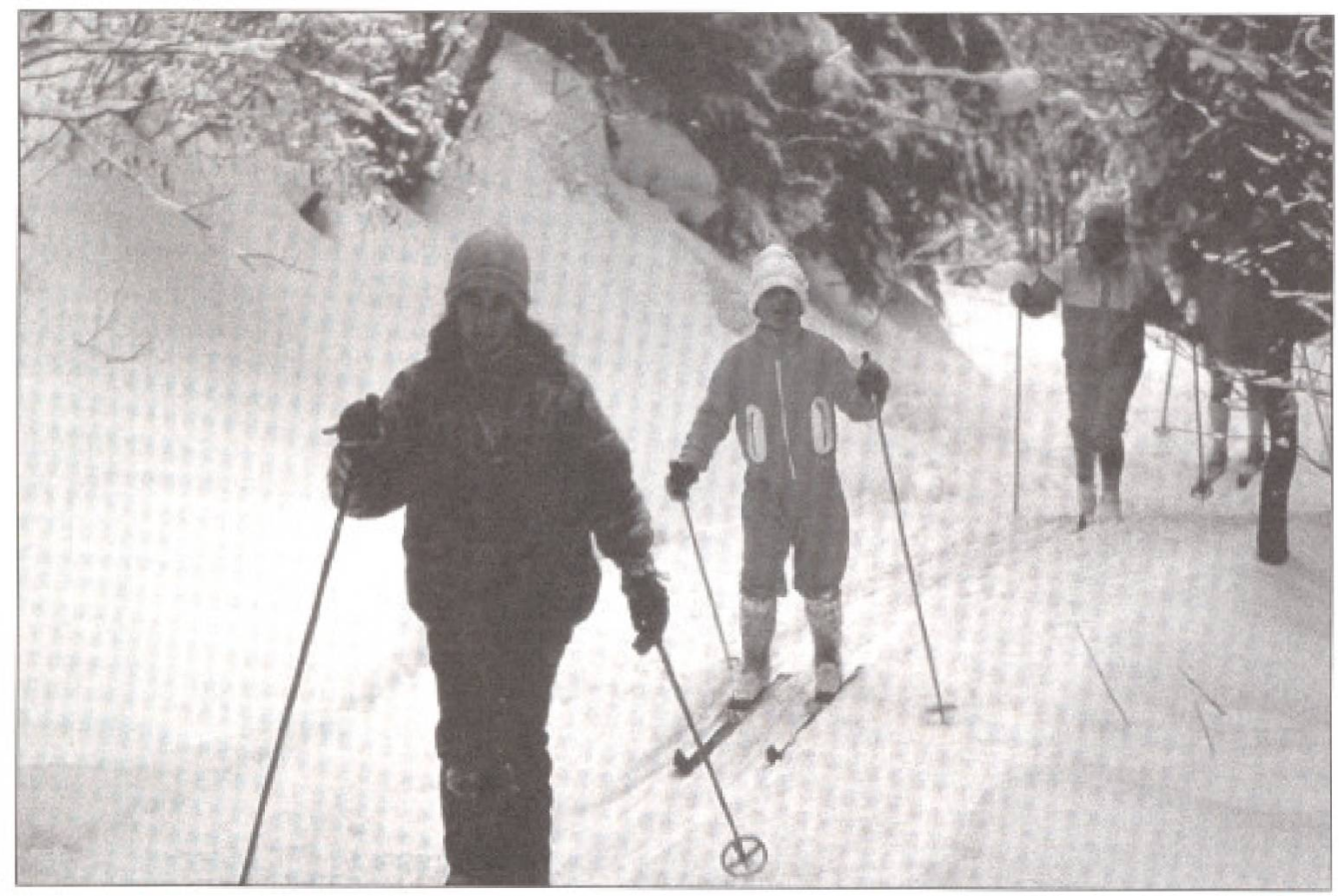

Leur contribution, note-t-il, "dans l'aménagement du territoire est souvent méconnuen et leurs retombées sociales et économiques winsuffisamment soulignées", même si les Laurentides, surtout celles de Montréal et de Lanaudière, concentrent l'essentiel de ces établissements au Québec. Cette contribution devrait donc être mieux prise en compte.

Que ce soit pour la villégiature, la pratique d'activités de plein air ou la fréquentation des établissements hôteliers petits ou grands. Christian Morissonneau relève que les Laurentides de Lanaudière et de Montréal niont pas attiré que les Canadiens frangais catholiques: "En beaucoup d'endroits, les anglophones et les représentants des autres ethnies ont lancé les premiers des fronts pionniers touristiques dans les sites attrayants des nappes $d^{\prime \prime e a u}$ et des montagnesw. Cette clientèle, soutient-il, ont "contribué a la construction des régions., selon deux modẻles de développement touristique et wune franche régionalisation qui permet à chacun des territoires de penser et de faire le tourisme différemment:

Qui pense aux Laurentides ne peut passer sous silence linfluence qu'ont eu le mont Tremblant et le P'tit train du Nord dans leur développement touristique. Sommet dominant, point d'ancrage du parc naturel et récréatif du même nom, aire de ski renommée depuis 1938, le mont Tremblant est resté uun géant endormi pendant une bonne vingtaine d'annéesn, observe Luc Tittley. Son réveil et sa réinsertion parmi les plus grandes destinations quatre-saisons d'Amérique du Nord depuis sa prise en main par Intrawest, tiennent, bien sûr, à "lomnipuissance de l'argent" mais également au respect de trois facteurs essentiels au succés: la vision, le savoir-faire ot rappui du milieu.

Le P'tit train du Nord, quant à lui devait être I"instrument privilégié de fessor économique des Paysd'en-Haut, via sa colonisation agricole. Tols étaient en tous cas la vision et le rêve du curé Labelle. L'histoire en décida autrement, et les touristes, davantage que les agriculteurs, déferlèrent sur la région. À son tour, le chemin de fer fut détrôné par la route, plus propice à l'autonomie des visiteurs. Laissée pour compte, abandonnée, l'emprise ferroviaire du P'tit train du Nord est devenue un symbole. celui de la réappropriation collective d'un équipement régional par la création d'un parc linéaire polyvalent, et une nouvelle avenue de développement touristique axé, entre autres, sur le contact avec la nature et le patrimoine batti

D'oủ ma conchsion, inspirée de ce qui se fait en d'autres régions du monde: "A l'instar du parc lui-même, devront être apportées des approches et solutions originales, particulièrement adaptées à son contexten. Cette réflexion s'applique d'ailleurs ả toutes les Laurentides dont la diversité appelle un élargissement de loptique et de la stratégie de développement touristique de la "grandes région des Laurentides. 